Research Article

\title{
Pet and Stray Dogs as Reservoirs of Antimicrobial-Resistant Escherichia coli
}

\author{
Laura Marchetti $\left(\mathbb{D},{ }^{1}\right.$ Daniel Buldain $\left(\mathbb{D},{ }^{1,2}\right.$ Lihuel Gortari Castillo $\mathbb{D D}^{1,2}$ \\ Andrea Buchamer $\mathbb{D}^{1},{ }^{1}$ Manuel Chirino-Trejo $\mathbb{D}^{\mathrm{D}},{ }^{3}$ and Nora Mestorino $\mathbb{D D}^{1}$ \\ ${ }^{1}$ Laboratorio de Estudios Farmacológicos y Toxicológicos (LEFyT), Facultad de Ciencias Veterinarias, \\ Universidad Nacional de La Plata, 60 y 118, 1900 La Plata, Argentina \\ ${ }^{2}$ Consejo Nacional de Investigaciones Científicas y Técnicas CONICET, Buenos Aires, Argentina \\ ${ }^{3}$ Department of Veterinary Microbiology, Western College of Veterinary Medicine, University of Saskatchewan, 52 Campus Dr, \\ Saskatoon SK S7N 5B4, Canada \\ Correspondence should be addressed to Nora Mestorino; nmestorino@yahoo.com
}

Received 10 October 2020; Revised 28 December 2020; Accepted 14 January 2021; Published 25 January 2021

Academic Editor: Sujata Prasad

Copyright (c) 2021 Laura Marchetti et al. This is an open access article distributed under the Creative Commons Attribution License, which permits unrestricted use, distribution, and reproduction in any medium, provided the original work is properly cited.

\begin{abstract}
The close contact between dogs and humans creates the best bridge for interspecies transmission of antimicrobial-resistant bacteria. The surveillance of its resistance including the detection of extended-spectrum beta-lactamases (ESBLs) in Escherichia coli as indicator bacteria is an important tool to control the use of antimicrobials. The aim of this research was to evaluate the $E$. coli resistance in strains by phenotypic methods, isolated from pet and stray dogs of La Plata city, Argentina. Faecal samples were collected using rectal swabs from 50 dogs with owners (home dogs $=$ HD) and 50 homeless dogs (stray dogs $=$ SD). They were cultured in 3 MacConkey agar plates, with and without antibiotics (ciprofloxacin and cefotaxime). 197 strains were isolated, of which only 95 strains were biochemically identified as E. coli, 46 strains were from HD, and 49 were from SD. Antimicrobial susceptibility was evaluated by the Kirby-Bauer disk diffusion method. The most prevalent resistance was for tetracycline, streptomycin, and ampicillin. In both groups, the level of resistance to 3rd generation cephalosporins was high, and there were multiresistant strains. There was a higher level of antimicrobial resistance in strains from SD compared to HD. There were $8 \%$ of strains suspected of being ESBLs among samples of HD and 36\% of SD. One (2\%) of the strains isolated from HD and 11 (22\%) from SD were phenotypically confirmed as ESBL. Pets and stray dogs are a potential source of $E$. coli antibiotic resistance in Argentina; therefore, its surveillance must be guaranteed.
\end{abstract}

\section{Introduction}

The role of pets as one of the most important disseminators of antimicrobial-resistant bacteria has been underestimated for a long time because the general focus has been aimed at food-producing animals as the principal source of resistant bacteria. However, the close contact between pets and humans creates the best bridge for interspecies transmission of multidrug-resistant (MDR) bacteria [1].

Dogs and cats which live in the same house with their owners make contact with the same surfaces and objects, and these habits increase the chances of antimicrobial resistance dissemination. Furthermore, veterinary practice evolution and the increasing sense of social responsibility for the welfare and health of pets have enhanced their life expectancy, which has increased the number of geriatric patients that frequently need antimicrobial therapy, since they often suffer from chronic diseases or immunocompromising conditions [2].

Antimicrobials are frequently used for therapeutic and prophylactic purposes, not only in dogs that live in homes but also in stray dogs. In Argentina, people without professional knowledge frequently administrate antimicrobials to stray dogs because of the unrestricted antibiotic sale and 
the increasing tendency to protect animals [3]. The inadequate use and abusive prescription of antibiotics, the application of subtherapeutic doses, the irregularity in the administration of antimicrobials, and the change in the social role of dogs among the community nowadays are important risk factors for antimicrobial resistance selection and the transference of bacteria with gene resistance determinants. Several studies have proved that antimicrobialresistant bacteria could be transferred from dogs to humans and from humans to dogs [4-6].

In recent years, there has been an important increment in the number of companion animals in Argentina. According to a recent study of the Department of Health and Animal Protection of the Government of Buenos Aires city, there are between 800000 and one million dogs and cats, with and without owners. This means that there is one pet for every 3 humans $[7,8]$.

Several resistance microorganisms have been isolated from healthy and sick pets, such as methicillin-resistant Staphylococcus aureus (MRSA), methicillin resistance Staphylococcus pseudintermedius (MRSP), multidrug-resistance Gram-negative bacteria, and extended-spectrum betalactamase (ESBL)/AmpC-producing Enterobacteriaceae $[9,10]$. The great increase in strains carrying ESBLs in humans, animals, and their surrounding environments is a huge problem worldwide. Companion animals would have a possible role as reservoirs for ESBLs [11].

ESBL genes in Escherichia coli are mainly encoded in plasmids; nevertheless, there are studies that confirmed chromosomal integration [12-14]. These enzymes have hydrolytic activity against penicillins, third-generation cephalosporins (ceftazidime or cefotaxime), and aztreonam, but not the cephamycins (cefoxitin) or carbapenems, and are inhibited by beta-lactamase inhibitors as clavulanic acid [15]. Beta-lactams are possibly the antimicrobials most widely used not only in human medicine but also in animals due to the safety, antimicrobial spectrum, availability, and pharmacokinetic and pharmacodynamic properties [16]. First-generation cephalosporins and amoxicillin with clavulanic acid and penicillin with an aminoglycoside are prescribed routinely in daily veterinary clinic practice. Thirdgeneration cephalosporins represent one of a few therapeutic options to treat bacterial infections of difficult resolution; therefore, they are critically important drugs.

Enterobacteriaceae are the main producers of ESBL, particularly Klebsiella pneumoniae and E. coli [17]. Among the intestinal microbiome, E. coli has a role as an indicator of resistance because it is one of the most widespread groups of intestinal bacteria. The surveillance of its resistance mechanisms is an important tool in the control of nonprudent use of antimicrobials. It allows us to know which antimicrobials are selected for antimicrobial resistance, avoiding public health risks, reducing therapeutic failures and economic losses among producers [5].

Furthermore, ESBL strains often carry antimicrobial resistance genes for other antibiotics, such as fluoroquinolones, aminoglycosides, tetracyclines, sulfamethoxazole-trimethoprim, and chloramphenicol. Consequently, there is a potential risk of cross-resistance mediated by plasmids, and there is a great concern because of the increasing emergence of different phenotypes of resistance such as multidrug resistance (MDR: when at least one agent in three or more families of antibiotics is not sensitive), extreme resistance (XDR) when they are not sensitive to at least one agent in all categories of antibacterial families except one or two of them), and pan-resistance (PDR: when they are not sensitive to any of the agents in all the antimicrobial categories) $[18,19]$.

The objectives of this research were to detect resistance patterns and in vitro ESBLs producing E. coli strains by phenotypic methods, isolated from dogs with owners and stray dogs of La Plata city, Buenos Aires, Argentina.

\section{Materials and Methods}

2.1. Bacterial Strains. 50 faecal samples of dogs living in houses with owners (home dogs $=\mathrm{HD}$ ) and 50 samples of homeless dogs (stray dogs $=\mathrm{SD}$ ) were collected from October to December 2016 in La Plata city, Buenos Aires, Argentina. Dogs with owners were clinically healthy, adults, and raised in family homes. They did not receive antimicrobial treatments in the last 3 months. For samples taken in a veterinary clinic, only those animals that come for routine health control or to reinforce vaccines by the health plan were selected. Stray dog faecal samples were collected in different areas of La Plata city following the spiral sampling method [20]. La Plata city is characterized by its particular design because it is a grid, a perfect square with two diagonals that cross the complete city from east to west and from north to south. Consequently, stray dogs were sampled beginning from the peripheral area to the centre of the square. Only nonaggressive stray dogs were chosen for sampling since no sedation method was used. Animals were restrained by two operators, and a third person took the rectal faecal sample using a sterile cotton swab.

The protocol was carried out according to the Guide for the Care and Use of Agricultural Animals in Agricultural Research and Teaching (Federation of Animal Science Societies-FASS-) [21] and was approved by the Experimental Ethics Committee of the Faculty of Veterinary Science, UNLP, Argentina (47.3.15 J).

In the laboratory, each cotton swab was used to inoculate each sample onto 3 agar plates: MacConkey agar (Difco, Becton Dickinson, USA) supplemented with $2 \mathrm{mg} / \mathrm{L}$ cefotaxime (plate A), MacConkey agar supplemented with $0.05 \mathrm{mg} / \mathrm{L}$ ciprofloxacin (plate B) to select possible resistant strains present in the samples, and the third plate without antimicrobial (plate C). Cefotaxime and ciprofloxacin were obtained from Sigma-Aldrich, MO, USA. After overnight incubation at $37^{\circ} \mathrm{C}, 2-3 \mathrm{col}-$ onies with the phenotypic characteristics of $E$. coli were selected, Gram stained, and typified by biochemical tests (Urease production, Catalase test, Motility, Voges Proskauer, Indole production, Carbohydrate fermentation tests, Methyl red, and Citrate utilization). E. coli ATCC $25922^{\circledR}$ (American Type Culture Collection, USA) was used as quality control $[22,23]$. 
2.2. Susceptibility Testing. The strains that grew in plates A and/or B were identified biochemically as E. coli and tested for antimicrobial susceptibility by the standard Kirby-Bauer disk diffusion method. But when there were no colonies on those plates (A or B) but in $\mathrm{C}$, strains developed in this last plate without antibiotic were isolated to study. Twenty antimicrobials (Becton Dickinson, USA) were selected: amoxicillin/clavulanic acid $(20 \mu \mathrm{g} / 10 \mu \mathrm{g})$, ampicillin $(10 \mu \mathrm{g})$, ampicillin-sulbactam $(10 \mu \mathrm{g} / 10 \mu \mathrm{g})$, ceftriaxone $(30 \mu \mathrm{g})$, ceftazidime $(30 \mu \mathrm{g})$, cefotaxime $(30 \mu \mathrm{g})$, cefazoline $(30 \mu \mathrm{g})$, cefpodoxime $(10 \mu \mathrm{g})$, sulfamethoxazole-trimethoprim $(23.75 \mu \mathrm{g} / 1.25 \mu \mathrm{g})$, chloramphenicol $(30 \mu \mathrm{g})$, ciprofloxacin $(5 \mu \mathrm{g})$, nalidixic acid $(30 \mu \mathrm{g})$, tetracycline $(30 \mu \mathrm{g})$, gentamicin $(10 \mu \mathrm{g})$, streptomycin $(10 \mu \mathrm{g})$, kanamycin $(30 \mu \mathrm{g})$, amikacin $(30 \mu \mathrm{g})$, nitrofurantoin $(30 \mu \mathrm{g})$, aztreonam $(30 \mu \mathrm{g})$, and imipenem $(10 \mu \mathrm{g})$, according to the Clinical and Laboratory Standards Institute, CLSI [22, 23].

2.3. ESBL Identification. The first ESBL disc screening test was evaluated using antibiotic discs of cefpodoxime, ceftazidime, aztreonam, cefotaxime, and ceftriaxone on Mueller Hinton agar (Britania, Argentine) [18, 19]. Results were interpreted according to CLSI screening cut-off values for the antimicrobials mentioned above. When the diameter around one of the disks mentioned was cefpodoxime $\leq 17 \mathrm{~mm}$, ceftazidime $\leq 22 \mathrm{~mm}$, cefotaxime $\leq 27 \mathrm{~mm}$, ceftriaxone $\leq 25 \mathrm{~mm}$, aztreonam $\leq 27 \mathrm{~mm}$, respectively, the isolations were considered suspected of ESBL phenotype $[22,23]$.

For the ESBL confirmation, the Double-Disc Synergy Test was applied according to CLSI 2013; discs containing ceftazidime and cefpodoxime were put next to a disc with amoxicillin plus clavulanic acid ( $20 \mathrm{~mm}$ centre to centre). The positive result is indicated when the inhibition zones around any of the cephalosporin discs were augmented in the direction of the disc containing clavulanic acid. E. coli ATCC $25922^{\circledR}$ was used for quality control $[22,23]$.

2.4. Statistical Analysis. Chi-square test was used to determine the significance of differences in resistance prevalence between stray dogs and pets. A value of $p \leq 0.05$ was considered significant.

\section{Results and Discussion}

197 strains were isolated (77 from HD and 120 from SD) from the 100 faecal samples. Only 95 strains biochemically identified as E. coli ( 46 from HD and 49 from SD) were studied; every strain was individual and becomes from one of the 3 plates mentioned above (A, B, or $\mathrm{C}$ ). From a few samples, we obtained isolations biochemically identified as E. coli from both plates A and B at the same time, but we studied them individually. They were chosen as follows: from samples of HD, 3 strains of $E$. coli grew on plate A (with cefotaxime), 19 grew on plate $B$ (with ciprofloxacin), and the rest of the strains $(n=24)$ only developed on agar without antimicrobials; on the other hand, from samples of SD, 19 strains of E. coli developed on plate A and 16 on plate B; the rest $(n=14)$ grew in the plates without antimicrobials (plate C).

Those strains that had grown on agar with cefotaxime (plate A) or with ciprofloxacin (plate B) were selected to carry out antibiograms. Strains of E. coli that were inhibited in plates $\mathrm{A}$ and $\mathrm{B}$ but developed in plate $\mathrm{C}$ without antimicrobial were the third group studied, including susceptibility test. Therefore, a total of 46 strains of dogs with owner and 49 without owner were selected for the study.

The most common resistance observed was to tetracycline $(70 \%)$ in SD-derived strains and to nalidixic acid (38.3\%) in HD-derived strains. Resistance to streptomycin (46\%) and ampicillin (44\%) was the second high in SD strains. For HD, there were $25.5 \%$ of resistance to ampicillin and $19.1 \%$ to sulfamethoxazole-trimethoprim. In both groups, the level of resistance to 3rd generation cephalosporins was high (ceftriaxone: 30\% SD-21.3\% HD and cefotaxime: $28 \%$ for SD). There was a higher level of antimicrobial resistance in strains from SD compared to HD. No E. coli from either group showed resistance to imipenem or nitrofurantoin. There were multiresistant strains in both groups, and their resistance profile includes one, two, three, and more than four antimicrobials (see Figure 1 and Table 1).

There were $8 \%$ of strains suspected of being ESBL among samples of HD and $36 \%$ of SD. One of the suspected ESBL strains from HD (2\%) and $11(22 \%)$ of SD were confirmed.

The most prevalent phenotypes of resistance detected among the $E$. coli isolates recovered from $\mathrm{HD}$ were nalidixic acid (NAL $=5$ isolates) and nalidixic acid with tetracycline (NAL + TET $=$ two isolates).

The multiresistance occurrence was considerably higher in SD strains, with $32.7 \%$ of MDR profiles to more than 4 antimicrobials. The most prevalent phenotypes detected for $\mathrm{SD}$ isolates were tetracycline (TET $=8$ isolates), and as $\mathrm{HD}$ strains, nalidixic acid with tetracycline $(\mathrm{NAL}+\mathrm{TET}=$ three isolates).

All the strains that showed resistance to 4 antimicrobials or more in both groups (HD and SD strains) belong to isolates that had previously developed in plates with antimicrobial (ciprofloxacin and cefotaxime) (see Tables 2 and 3).

In our study, samples were obtained from faeces of animals with and without owners, but they were not clinical samples because the principal aim of our work was to know the prevalence of antimicrobial resistance in E. coli as indicator bacteria in La Plata city, in dogs without recent antimicrobial therapy. Most authors have published results obtained from clinical samples such as urine, urinary tract, intestinal tract, and ears [24-26]. This makes it difficult to compare results since there is an expected difference in the prevalence of resistance between populations of sick and healthy dogs.

Resistance to antimicrobials in the present study appeared to be higher than those previously reported in other studies done with healthy dogs. The highest level of resistance obtained was for tetracycline in SD-derived strains but not in pets $(p<0.0001)$. Ampicillin was the second most prevalent resistance observed $(\mathrm{SD}=44 \%$; 


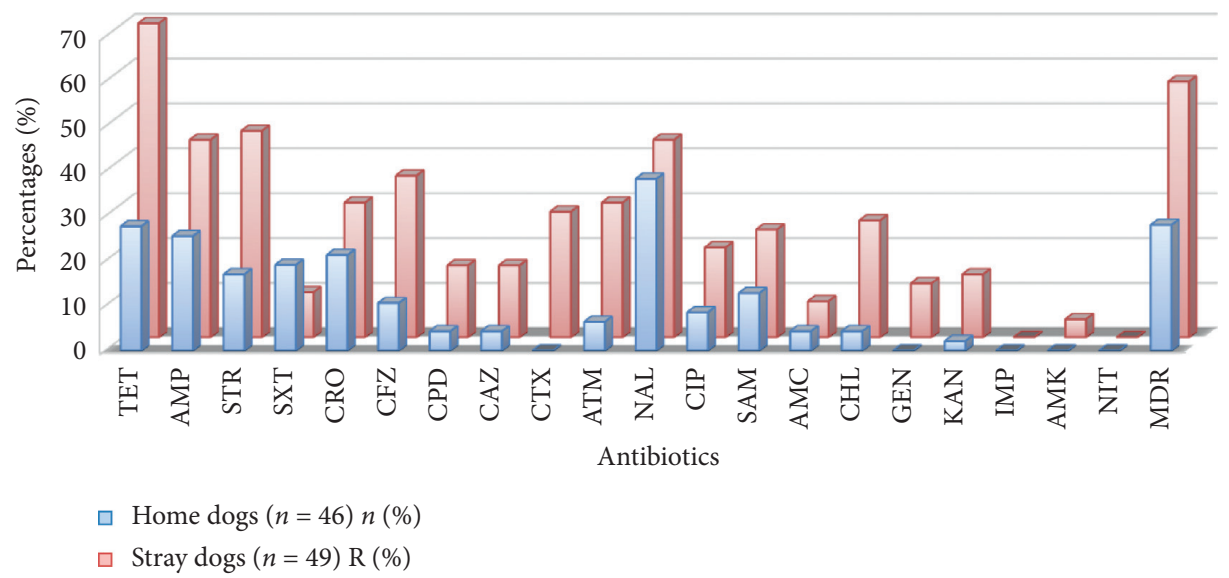

FIgure 1: Antimicrobial resistance percentages in home dog and stray dog strains. TET (tetracycline), AMP (ampicillin), STR (streptomycin), STX (sulfamethoxazole-trimethoprim), CRO (ceftriaxone), CFZ (cefazolin), CPD (cefpodoxime), CAZ (ceftazidime), CTX (cefotaxime), ATM (aztreonam), NAL (nalidixic acid), CIP (ciprofloxacin), SAM (ampicillin-sulbactam), AMC (amoxicillin-clavulanic acid), CHL (chloramphenicol), GEN (gentamicin), KAN (kanamycin), IMP (imipenem), AMK (amikacin), NIT (nitofuratoin), MDR (multidrug-resistant).

TABle 1: Prevalence of antimicrobial resistance E. coli isolated from pets and stray dogs.

\begin{tabular}{|c|c|c|c|c|}
\hline \multirow{3}{*}{ Antimicrobial agents } & \multicolumn{4}{|c|}{ Antimicrobial-resistant E. coli isolated from } \\
\hline & \multicolumn{2}{|c|}{ Home dogs $(n=46)$} & \multicolumn{2}{|c|}{ Stray dogs $(n=49)$} \\
\hline & Number & Percentage & Number & Percentage \\
\hline Tetracycline $^{\mathrm{a}}$ & 13 & 27.7 & 35 & 70 \\
\hline Ampicillin & 12 & 25.5 & 22 & 44 \\
\hline Streptomycin $^{\mathrm{a}}$ & 8 & 17 & 23 & 46 \\
\hline Sulfamethoxazole-Trimethoprim & 9 & 19.1 & 5 & 10 \\
\hline Ceftriaxone & 10 & 21.3 & 15 & 30 \\
\hline Cefazolin $^{\mathrm{a}}$ & 5 & 10.6 & 18 & 36 \\
\hline Cefpodoxime & 2 & 4.3 & 8 & 16 \\
\hline Ceftazidime & 2 & 4.3 & 8 & 16 \\
\hline Cefotaxime $^{\mathrm{a}}$ & 0 & 0 & 14 & 28 \\
\hline Aztreonam $^{\mathrm{a}}$ & 4 & 6.4 & 15 & 30 \\
\hline Nalidixic acid & 18 & 38.3 & 22 & 44 \\
\hline Ciprofloxacin & 4 & 8.5 & 10 & 20 \\
\hline Ampicillin-sulbactam & 6 & 12.8 & 12 & 24 \\
\hline Amoxicillin-clavulanic & 2 & 4.3 & 4 & 8 \\
\hline Chloramphenicol $^{\mathrm{a}}$ & 2 & 4.3 & 13 & 26 \\
\hline Gentamicin $^{\mathrm{a}}$ & 0 & 0 & 6 & 12 \\
\hline Kanamycin $^{\mathrm{a}}$ & 1 & 2.1 & 7 & 14 \\
\hline Imipenem & 0 & 0 & 0 & 0 \\
\hline Amikacin & 0 & 0 & 2 & 4 \\
\hline Nitrofurantoin & 0 & 0 & 0 & 0 \\
\hline R 1 ATM & 8 & 17.4 & 9 & 18.4 \\
\hline R 2 ATMs & 5 & 10.9 & 5 & 10.2 \\
\hline R 3 ATMs & 2 & 4.3 & 5 & 10.2 \\
\hline R 4 or more ATMs & 11 & 23.9 & 23 & 32.7 \\
\hline
\end{tabular}

${ }^{a} p \leq 0.05$; R 1 ATM (resistance to only one antimicrobial); R 2 ATMs (resistance to two antimicrobials only); R 3 ATMs (resistance to three antimicrobials only); R 4 or more ATMs (resistance to four or more antimicrobials).

$\mathrm{HD}=25.5 \%)$; however, it was not quite significant ( $p=0.8888)$. Resistance to nalidixic acid was common in both groups of animals ( $\mathrm{HD}=38.3 \%$; $\mathrm{SD}=44 \%$ ), considered not significant $(p=0.6798)$. Stray dog isolates also showed high resistance against streptomycin (46\%), but it was low $(17 \%)$ in pets $(p<0.0001)$. Resistance to ampicillin and tetracycline is the most frequently reported in most studies made with healthy dogs, in different countries [27-29]. The resistance percentages obtained for the antimicrobials mentioned above in pet strains (HD) are similar to those reported in a study of Wedley et al. [27], from healthy dogs living in a semirural community in Cheshire, UK (24\% for ampicillin and $19.7 \%$ for tetracycline). In another study carried out in dogs visiting veterinarians from the UK, they 
TABle 2: Phenotypes of resistance detected among the E. coli isolates recovered from pets.

\begin{tabular}{|c|c|c|}
\hline Phenotype of resistance & Number of isolates & Percentage of isolates \\
\hline $\mathrm{CRO}$ & 1 & 2.17 \\
\hline STR & 1 & 2.17 \\
\hline ATM & 1 & 2.17 \\
\hline $\mathrm{NAL}^{\mathrm{a}}$ & 5 & 10.8 \\
\hline $\mathrm{KAN}+\mathrm{NAL}$ & 1 & 2.17 \\
\hline $\mathrm{TET}+\mathrm{STR}$ & 1 & 2.17 \\
\hline $\mathrm{NAL}+\mathrm{TET}^{\mathrm{a}}$ & 2 & 4.3 \\
\hline $\mathrm{NAL}+\mathrm{CRO}$ & 1 & 2.17 \\
\hline $\mathrm{AMC}+\mathrm{CFZ}+\mathrm{AMP}$ & 1 & 2.17 \\
\hline $\mathrm{SXT}+\mathrm{CFZ}+\mathrm{AMP}$ & 1 & 2.17 \\
\hline $\mathrm{SXT}+\mathrm{CIP}+\mathrm{NAL}+\mathrm{TET}^{\mathrm{a}}$ & 1 & 2.17 \\
\hline $\mathrm{STX}+\mathrm{NAL}+\mathrm{TET}+\mathrm{STR}^{\mathrm{a}}$ & 1 & 2.17 \\
\hline $\mathrm{SXT}+\mathrm{TET}+\mathrm{STR}+\mathrm{AMP}+\mathrm{CRO}^{\mathrm{a}}$ & 1 & 2.17 \\
\hline $\mathrm{STX}+\mathrm{TET}+\mathrm{STR}+\mathrm{AMP}+\mathrm{CRO}^{\mathrm{a}}$ & 1 & 2.17 \\
\hline $\mathrm{NA}+\mathrm{TET}+\mathrm{STR}+\mathrm{AMP}+\mathrm{CRO}^{\mathrm{a}}$ & 1 & 2.17 \\
\hline $\mathrm{STX}+\mathrm{CFZ}+\mathrm{NAL}+\mathrm{TET}+\mathrm{AMP}^{\mathrm{a}}$ & 1 & 2.17 \\
\hline $\mathrm{SXT}+\mathrm{SAM}+\mathrm{CIP}+\mathrm{NAL}+\mathrm{TET}+\mathrm{AMP}^{\mathrm{a}}$ & 1 & 2.17 \\
\hline $\mathrm{STX}+\mathrm{SAM}+\mathrm{CIP}+\mathrm{NAL}+\mathrm{TET}+\mathrm{STR}+\mathrm{AMP}^{\mathrm{a}}$ & 1 & 2.17 \\
\hline $\mathrm{STX}+\mathrm{SAM}+\mathrm{NAL}+\mathrm{TET}+\mathrm{AMP}+\mathrm{CRO}+\mathrm{ATM}^{\mathrm{a}}$ & 1 & 2.17 \\
\hline $\mathrm{CTX}+\mathrm{CFZ}+\mathrm{SAM}+\mathrm{CPD}+\mathrm{CRO}+\mathrm{CIP}+\mathrm{NAL}+\mathrm{AMP}+\mathrm{CRO}^{\mathrm{b}}$ & 1 & 2.17 \\
\hline $\mathrm{CAZ}+\mathrm{CTX}+\mathrm{AMC}+\mathrm{CFZ}+\mathrm{SAM}+\mathrm{CIP}+\mathrm{CRO}+\mathrm{AMP}+\mathrm{ATM}^{\mathrm{b}}$ & 1 & 2.17 \\
\hline
\end{tabular}

${ }^{\mathrm{a}}$ E. coli developed on the plate with ciprofloxacin; ${ }^{\mathrm{b}}$ E. coli developed on the plate with cefotaxime. TET, tetracycline; AMP, ampicillin; STR, streptomycin; STX, sulfamethoxazole-trimethoprim; CRO, ceftriaxone; CFZ, cefazolin; CPD, cefpodoxime; CAZ, ceftazidime; CTX, cefotaxime; ATM, aztreonam; NAL, nalidixic acid; CIP, ciprofloxacin; SAM, ampicillin-sulbactam; AMC, amoxicillin-clavulanic acid; GEN, gentamicin; KAN, kanamycin.

found a higher level of resistance for both antibiotics; $37.2 \%$ of the isolates were resistant to ampicillin and $30 \%$ to tetracycline [28]. Nevertheless, these results are still lower than those reported for SD isolates in our work. The results reported by Costa et al. [30], in healthy pets from Portugal isolates, were even lower: $20.5 \%$ of resistance for tetracyclines and $7.7 \%$ for ampicillin. Interestingly, in some studies done with clinical isolates, in the $E$. coli isolated from urinary infections, septicaemia, and skin and soft tissue infections, the resistance to ampicillin and tetracycline was lower than that of our results $[24,31]$.

Beta-lactams and tetracyclines are the antimicrobials more used in pets; the different levels of resistance reported in every work correlate with the frequency and magnitude of their use in different countries. Furthermore, our results are disturbing because they demonstrate that in La Plata it seems to be an abuse and/or misuse of broad-spectrum antimicrobials such as tetracyclines, as well as beta-lactams.

The identification of ESBLs producing strains is very important to guide an adequate antimicrobial therapy. There were $8 \%$ of strains suspected of being ESBLs among samples of $\mathrm{HD}$ and $36 \%$ from SD. One of the ESBL strains suspected from $\mathrm{HD}(2 \%)$ and $11(22 \%)$ of SD were confirmed by phenotypic tests, but there was no genetic confirmation, which is a limitation in our study. Again, the results obtained for HD strains are similar to those published by Wedley et al. $[27,28]$, but the percentage of ESBL in SD strains was considerably higher.

The prevalence of multidrug resistance (resistance to more than 3 antimicrobials) was considerably higher in SD strains, compared to several studies published by other authors [27, 28, 32-34]. In pet strains (HD), there was a similar percentage $(28 \%)$ of $\mathrm{MDR}$ to those reported by Murphy et al. [34], in a study made on healthy dogs from Canada. Again, the findings in SD strains are a big concern. Antimicrobials can be acquired without a professional prescription in Argentina. This is one of the possible reasons that lead to the administration of them by anyone, even without being a veterinarian. Another possible source of antimicrobial resistance transmission is the garbage; stray dogs break the garbage bags and eat them. It is possible that bacteria contained in those bags carry antimicrobial resistance genes. On the other hand, household antibiotic waste contaminates the nonhome environment, selecting antimicrobial resistance in bacteria there, which then infect stray dogs and other humans. In Argentina, data are extremely limited for the amount of antimicrobial-resistant bacteria on pets and in the near-home environment. Furthermore, whilst antimicrobials are monitored in stuff entering the formal market, there is a significant informal market, and antimicrobial levels in the environment are not routinely measured. One potential response to the rising threat of antimicrobial resistance is regulation, and both international organizations-led by the $\mathrm{WHO}$ - and individual countries have sought to formulate, for example, new regulatory frameworks to address the use of antimicrobials, as well as the household waste management. The source of the resistance genes in those bacteria of stray dogs is still unknown, and further studies should be done to detect such environmental source(s).

One of the most prevalent phenotypes detected for SD and $\mathrm{HD}$ isolates was nalidixic acid with tetracycline $(\mathrm{NAL}+\mathrm{TET}=$ three isolates $)$. Those strains were $\mathrm{NAL}^{\mathrm{R}} \mathrm{CIP}^{\mathrm{S}}$; it means that they were resistant to nalidixic acid and 
TABle 3: Phenotypes of resistance detected among the E. coli isolates recovered from stray dogs.

\begin{tabular}{|c|c|c|}
\hline Phenotype of resistance & Number of isolates & Percentage of isolates \\
\hline $\operatorname{TET}^{\mathrm{a}(1)}$ & 8 & 16.3 \\
\hline $\mathrm{NA}^{\mathrm{b}}$ & 1 & 2.04 \\
\hline $\mathrm{STX}+\mathrm{CZ}$ & 1 & 2.04 \\
\hline $\mathrm{NAL}+\mathrm{TET}^{\mathrm{a}}$ & 3 & 6.12 \\
\hline $\mathrm{SAM}+\mathrm{AMP}^{\mathrm{a}}$ & 1 & 2.04 \\
\hline $\mathrm{CFZ}+\mathrm{STR}+\mathrm{ATM}^{\mathrm{a}}$ & 2 & 4.08 \\
\hline TET + STR + CRO & 1 & 2.04 \\
\hline TET + STR + AMP & 1 & 2.04 \\
\hline $\mathrm{TET}+\mathrm{AMP}+\mathrm{CRO}^{\mathrm{a}}$ & 1 & 2.04 \\
\hline $\mathrm{TET}+\mathrm{STR}+\mathrm{AMP}+\mathrm{CRO}^{\mathrm{a}}$ & 1 & 2.04 \\
\hline $\mathrm{CAZ}+\mathrm{CTX}+\mathrm{NA}+\mathrm{TET}+\mathrm{STR}^{\mathrm{b}}$ & 1 & 2.04 \\
\hline $\mathrm{CIP}+\mathrm{NA}+\mathrm{TET}+\mathrm{STR}+\mathrm{AMP}^{\mathrm{a}}$ & 1 & 2.04 \\
\hline $\mathrm{CIP}+\mathrm{NA}+\mathrm{TET}+\mathrm{STR}+\mathrm{AMP}+\mathrm{CRO}^{\mathrm{a}}$ & 2 & 4.08 \\
\hline $\mathrm{CAZ}+\mathrm{CTX}+\mathrm{NA}+\mathrm{TET}+\mathrm{STR}+\mathrm{AMP}+\mathrm{CRO}^{\mathrm{a}}$ & 1 & 2.04 \\
\hline $\mathrm{CPD}+\mathrm{CIP}+\mathrm{NAL}+\mathrm{TET}+\mathrm{STR}+\mathrm{AMP}+\mathrm{CRO}^{\mathrm{a}}$ & 1 & 2.04 \\
\hline $\mathrm{SXT}+\mathrm{KAN}+\mathrm{NAL}+\mathrm{TET}+\mathrm{GEN}+\mathrm{STR}+\mathrm{AMP}+\mathrm{CRO}^{\mathrm{a}}$ & 1 & 2.04 \\
\hline $\mathrm{CAZ}+\mathrm{CTX}+\mathrm{CFZ}+\mathrm{CRO}+\mathrm{KAN}+\mathrm{NAL}+\mathrm{TET}+\mathrm{ATM}^{\mathrm{b}}$ & 1 & 2.04 \\
\hline $\mathrm{CTX}+\mathrm{CFZ}+\mathrm{SAM}+\mathrm{CPD}+\mathrm{CRO}+\mathrm{KAN}+\mathrm{TET}+\mathrm{GEN}^{\mathrm{b}}$ & 1 & 2.04 \\
\hline $\mathrm{CAZ}+\mathrm{AMC}+\mathrm{CFZ}+\mathrm{SAM}+\mathrm{CPD}+\mathrm{TET}+\mathrm{STR}+\mathrm{AMP}+\mathrm{ATM}^{\mathrm{b}}$ & 1 & 2.04 \\
\hline $\mathrm{CAZ}+\mathrm{AMK}+\mathrm{CFZ}+\mathrm{CRO}+\mathrm{KAN}+\mathrm{NAL}+\mathrm{GEN}+\mathrm{STR}+\mathrm{ATM}^{\mathrm{b}}$ & 1 & 2.04 \\
\hline $\mathrm{CTX}+\mathrm{CFZ}+\mathrm{SAM}+\mathrm{CRO}+\mathrm{KAN}+\mathrm{TET}+\mathrm{GEN}+\mathrm{STR}+\mathrm{AMP}+\mathrm{ATM}^{\mathrm{b}}$ & 1 & 2.04 \\
\hline $\mathrm{CTX}+\mathrm{CFZ}+\mathrm{SAM}+\mathrm{CPD}+\mathrm{CRO}+\mathrm{NAL}+\mathrm{TET}+\mathrm{STR}+\mathrm{AM}+\mathrm{CRO}$ & 1 & 2.04 \\
\hline $\mathrm{CTX}+\mathrm{CFZ}+\mathrm{SAM}+\mathrm{CTD}+\mathrm{CRO}+\mathrm{NA}+\mathrm{TET}+\mathrm{STR}+\mathrm{AMP}+\mathrm{CRO}^{\mathrm{b}}$ & 1 & 2.04 \\
\hline $\mathrm{CTX}+\mathrm{CFZ}+\mathrm{SAM}+\mathrm{CRO}+\mathrm{KAN}+\mathrm{NAL}+\mathrm{GEN}+\mathrm{STR}+\mathrm{AMP}+\mathrm{ATM}^{\mathrm{b}}$ & 1 & 2.04 \\
\hline $\mathrm{CTX}+\mathrm{SXT}+\mathrm{CFZ}+\mathrm{CRO}+\mathrm{CIP}+\mathrm{NAL}+\mathrm{TET}+\mathrm{STR}+\mathrm{AMP}+\mathrm{ATM}^{\mathrm{b}}$ & 2 & 4.08 \\
\hline $\mathrm{CTX}+\mathrm{CFZ}+\mathrm{SAM}+\mathrm{CPD}+\mathrm{CRO}+\mathrm{KAN}+\mathrm{TET}+\mathrm{GEN}+\mathrm{STR}+\mathrm{AMP}+\mathrm{ATM}^{\mathrm{a}}$ & 1 & 2.04 \\
\hline $\mathrm{CAZ}+\mathrm{CTX}+\mathrm{AMC}+\mathrm{CFZ}+\mathrm{SAM}+\mathrm{CRO}+\mathrm{CIP}+\mathrm{NAL}+\mathrm{TET}+\mathrm{AMP}+\mathrm{CRO}+\mathrm{ATM}^{\mathrm{b}}$ & 1 & 2.04 \\
\hline $\mathrm{CAZ}+\mathrm{CTX}+\mathrm{AMC}+\mathrm{CFZ}+\mathrm{SAM}+\mathrm{CRO}+\mathrm{CIP}+\mathrm{NAL}+\mathrm{TET}+\mathrm{STR}+\mathrm{AMP}+\mathrm{CRO}+\mathrm{ATM}^{\mathrm{a} \cdot \mathrm{b}}$ & 2 & 4.08 \\
\hline $\mathrm{CAZ}+\mathrm{CTX}+\mathrm{SXT}+\mathrm{AMK}+\mathrm{CFZ}+\mathrm{SAM}+\mathrm{CPD}+\mathrm{CRO}+\mathrm{CIP}+\mathrm{NAL}+\mathrm{TET}+\mathrm{AMP}+\mathrm{ATM}^{\mathrm{a}}$ & 1 & 2.04 \\
\hline
\end{tabular}

${ }^{\mathrm{a}} E$. coli developed on the plate with ciprofloxacin; $\mathrm{TET}^{\mathrm{a}(1)}$ One $E$. coli developed on the plate with ciprofloxacin; ${ }^{\mathrm{b}} E$. coli developed on the plate with cefotaxime. TET, tetracycline; AMP, ampicillin; STR, streptomycin; STX, sulfamethoxazole-trimethoprim; CRO, ceftriaxone; CFZ, cefazolin; CPD, cefpodoxime; CAZ, ceftazidime; CTX, cefotaxime; ATM, aztreonam; NAL, nalidixic acid; CIP, ciprofloxacin; SAM, ampicillin-sulbactam; AMC, amoxicillin-clavulanic acid; CHL, chloramphenicol; GEN, gentamicin; KAN, kanamycin; AMK, amikacin.

susceptible to ciprofloxacin. This is a frequent finding in daily veterinary clinic laboratory. The mechanisms of resistance to quinolones are target alterations or efflux pump overexpression. The most relevant mechanism is the mutation of genes encoding quinolone targets (DNA gyrase and topoisomerase IV). The mutation on a point of the gyrA gene is frequently in $E$. coli clinical strains and has been associated with this phenotype $\mathrm{NAL}^{\mathrm{R}} \mathrm{CIP}^{\mathrm{S}}$. Bacteria that have this kind of mutation have shown to develop more frequently higher levels of resistance in the presence of quinolones [35].

\section{Conclusions}

It is very important to know the prevalence of antimicrobial resistance by surveillance studies not only in pets but also in homeless dogs. The unrestricted antibiotic sale, weak management of household waste, and the increasing tendency to protect animals in Argentina are important risk factors for antimicrobial resistance selection and the transference of gene resistance determinants among bacteria from pets, homeless dogs, and humans. The results of the present study indicate that similar studies in other cities of Argentina would be very useful for monitoring antimicrobial resistance at the national level.

\section{Data Availability}

The data used to support the findings of this study are available from Laboratorio de Estudios Farmacológicos y Toxicológicos -LEFyT-, Facultad de Ciencias Veterinarias, Universidad Nacional de La Plata upon request (nmestorino@yahoo.com, noram@fcv.unlp.edu.ar, mlauramarchetti@yahoo.com.ar, and mlmarchetti@fcv.unlp.edu.ar).

\section{Conflicts of Interest}

All the authors declare that there are no conflicts of interest regarding the publication of this paper.

\section{References}

[1] European Medicines Agency (EMA), Reflection Paper on the Risk of Antimicrobial Resistance Transfer from Companion Animals, Committee for Medicinal Products for Veterinary Use (CVMP), Amsterdam, Netherlands, 2015, http://www.ema. europa.eu/en/documents/scientific-guideline/draft-reflectionpaper-risk-antimicrobial-resistance-transfer-companion-animals_ en.pdf EMA/CVMP/AWP/401740/2013.

[2] P. Da Costa, L. Loureiro, and A. Matos, "Transfer of multidrug-resistant bacteria between intermingled ecological 
niches: the interface between humans, animals and the environment," International Journal of Environmental Research and Public Health, vol. 10, no. 1, pp. 278-294, 2013.

[3] Organización Panamericana de Salud [Internet], Legislación sobre antibióticos en América Latina, OPS, Washington, DC, USA, 2004, http://www.paho.org/spanish/ad/dpc/cd/amrlegis.pdf.

[4] C. Westgarth, G. L. Pinchbeck, J. W. S. Bradshaw, S. Dawson, R. M. Gaskell, and R. M. Christley, "Dog-human and dog-dog interactions of 260 dog-owning households in a community in Cheshire," Veterinary Record, vol. 162, no. 14, pp. 436-442, 2008.

[5] B. M. Marshall, D. J. Ochieng, and S. B. Levy, "Commensals: underappreciated reservoir of antibiotic resistance," Microbe Magazine, vol. 4, no. 5, pp. 231-238, 2009.

[6] C. Pomba, M. Rantala, C. Greko et al., "Public health risk of antimicrobial resistance transfers from companion animals," Journal of Antimicrobial Chemotherapy, vol. 72, no. 4, pp. 957-968, 2017.

[7] Gobierno de la ciudad de Buenos Aires, Informe módulo de tenencia responsable y sanidad de perros y gatos, pp. 1-26, Encuesta Anual de Hogares 2014, 2016, http://www. estadisticaciudad.gob.ar/eyc/wpcontent/uploads/2016/02/ eah_2014_tenencia_responsable_perros_gatos.pdf.

[8] E. Faro, C. Blanco, and J. Cuatrin, "Caninos y felinos en condición de calle: Relevamiento estadístico en la Ciudad Autónoma de Buenos Aires," Ciencia Veterinaria, vol. 19, no. 2, pp. 53-58, 2017.

[9] L. H. Wieler, C. Ewers, S. Guenther, B. Walther, and A. LübkeBecker, "Methicillin-resistant Staphylococci (MRS) and Extended-Spectrum Beta-Lactamases (ESBL)-producing Enterobacteriaceae in companion animals: nosocomial infections as one reason for the rising prevalence of these potential zoonotic pathogens in clinical samples," International Journal of Medical Microbiology, vol. 301, no. 8, pp. 635-641, 2011.

[10] C. Ewers, A. Bethe, I. Stamm et al., "CTX-M-15-D-ST648 Escherichia coli from companion animals and horses: another pandemic clone combining multiresistance and extraintestinal virulence?" Journal of Antimicrobial Chemotherapy, vol. 69, no. 5, pp. 1224-1230, 2014.

[11] A. L. Zogg, S. Simmen, K. Zurfluh, R. Stephan, S. N. Schmitt, and M. Nüesch-Inderbinen, "High prevalence of extendedspectrum $\beta$-lactamase producing enterobacteriaceae among clinical isolates from cats and dogs admitted to a veterinary hospital in Switzerland," Frontiers in Veterinary Science, vol. 5, pp. 1-8, 2018.

[12] I. Rodriguez, K. Thomas, A. Van Essen et al., "Chromosomal location of blaCTX-M genes in clinical isolates of Escherichia coli from Germany, the Netherlands and the UK," International Journal of Antimicrobial Agents, vol. 43, no. 9, pp. 553-557, 2014.

[13] I. Hirai, N. Fukui, M. Taguchi et al., "Detection of chromosomal blaCTX-M-15 in Escherichia coli O25b-B2-ST131 isolates from the Kinki region of Japan," International Journal of Antimicrobial Agents.vol. 42, no. 10, pp. 500-506, 2013.

[14] J. Ferreira, R. Penha Filho, L. Andrade, A. Berchieri, and A. Darini, "Detection of chromosomal blaCTX-M-2 in diverse Escherichia coli isolates from healthy broiler chickens," Clinical Microbiology and Infection, vol. 20, no. 6, pp. 623626, 2014.

[15] S. Ur Rahman, T. Ali, I. Ali, N. A. Khan, B. Han, and J. Gao, "The growing genetic and functional diversity of extended spectrum beta-lactamases," BioMed Research International, vol. 2018, Article ID 9519718, 14 pages, 2018.
[16] L. A. Hughes, N. Williams, P. Clegg et al., "Cross-sectional survey of antimicrobial prescribing patterns in UK small animal veterinary practice," Preventive Veterinary Medicine, vol. 104, no. 3-4, pp. 309-316, 2012.

[17] J. Kaur, G. Mahajan, K. Chand, and S. Sheevani Chopra, "Enhancing phenotypic detection of ESBL in AmpC coproducers by using Cefepime and Tazobactam," Journal of Clinical Diagnosis and Research, vol. 10, no. 1, pp. DC05-DC0, 2016.

[18] A.-P. Magiorakos, A. Srinivasan, R. B. Carey et al., "Multidrug-resistant, extensively drug-resistant and pandrug-resistant bacteria: an international expert proposal for interim standard definitions for acquired resistance," Clinical Microbiology and Infection, vol. 18, no. 3, pp. 268-281, 2012.

[19] M. Yasir, A. M. Ajlan, S. Shakil et al., "Molecular characterization, antimicrobial resistance and clinico-bioinformatics approaches to address the problem of extended-spectrum $\beta$-lactamase-producing Escherichia coli in western Saudi Arabia," Scientific Reports, vol. 8, no. 1, pp. 1-14, 2018.

[20] M. Wieczorkowski, "Spiral sampling as a fast way of data acquisition in surface topography," International Journal of Machine Tools and Manufacture, vol. 41, pp. 2017-2022, 2001.

[21] Federation of Animal Science Societies, Guide for the Care and Use of Agricultural Animals in Research and Teaching, Federation of Animal Science Societies, Champaign, Il, USA, 2010, https://www.asas.org/docs/default-source/defaultdocument-library/ag_guide_3rded.pdf?sfvrsn=4, Third Edition.

[22] Clinical and Laboratory Standards Institute (CLSI), Performance Standards for Antimicrobial Disk and Dilution Susceptibility Tests for Bacteria Isolated from Animals; 2nd Informational Supplement, Clinical and Laboratory Standards Institute, Wayne, PA, USA, CLSI document VET01-S2, 2013.

[23] Clinical and Laboratory Standards Institute (CLSI), Performance Standards for Antimicrobial Susceptibility Testing, Clinical and Laboratory Standards Institute, Wayne, PA, USA, CLSI supplement M100, 28th edition, 2018.

[24] K. J. Cummings, V. A. Aprea, and C. Altier, "Antimicrobial resistance trends among canine Escherichia coli isolates obtained from clinical samples in the northeastern USA, 2004-2011," The Canadian Veterinary Journal = La Revue Veterinaire Canadienne, vol. 56, no. 4, pp. 393-398, 2015.

[25] M. P. Sánchez, N. P. Gutiérrez, M. Y. Padilla, and L. L. Suárez, "Resistencia antimicrobiana de bacterias aisladas de clínicas veterinarias de la ciudad de Ibagué, Colombia," Revista Universidad Y Salud, vol. 17, no. 1, pp. 18-31, 2015.

[26] D. N. Qekwana, L. Phophi, V. Naidoo, J. W. Oguttu, and A. Odoi, "Antimicrobial resistance among Escherichia coli isolates from dogs presented with urinary tract infections at a veterinary teaching hospital in South Africa," BMC Veterinary Research, vol. 14, no. 1, pp. 2-6, 2018.

[27] A. L. Wedley, T. W. Westgarth, C. K. P. Coyne, G. L. Pinchbeck, N. J. Williams, and S. Dawson, "Prevalence of antimicrobial-resistant Escherichia coli in dogs in a crosssectional, community-based study," Veterinary Record, vol. 168, no. 13, p. 354, 2011.

[28] A. L. Wedley, S. Dawson, T. W. Maddox et al., "Carriage of antimicrobial resistant Escherichia coli in dogs: prevalence, associated risk factors and molecular characteristics," Veterinary Microbiology, vol. 199, pp. 23-30, 2017.

[29] J. A. Bourne, W. L. Chong, and D. M. Gordon, "Genetic structure, antimicrobial resistance and frequency of human associated Escherichia coli sequence types among faecal 
isolates from healthy dogs and cats living in Canberra", Australia," Plos One, vol. 14, no. 3, pp. 1-13, 2019.

[30] D. Costa, P. Poeta, Y. Sáenz et al., "Prevalence of antimicrobial resistance and resistance genes in faecal Escherichia coli isolates recovered from healthy pets," Veterinary Microbiology, vol. 127, no. 1-2, pp. 97-105, 2008.

[31] S. Saputra, D. Jordan, T. Mitchell et al., "Antimicrobial resistance in clinical Escherichia coli isolated from companion animals in Australia," Veterinary Microbiology, vol. 211, pp. $43-50,2017$.

[32] E. M. Turnidge, A. Decostere, L. A. Devriese, and F. Haesebrouck, "Antibiotic resistance among fecal indicator bacteria from healthy individually owned and kennel dogs," Microbial Drug Resistance, vol. 10, no. 1, pp. 65-69, 2004.

[33] V. M. D’Costa, K. M. McGrann, D. W. Hughes, and G. D. Wright, "Sampling the antibiotic resistome," Science, vol. 311 , no. 5759, pp. 374-377, 2006.

[34] C. Murphy, R. J. Reid-smith, J. F. Prescott et al., "Occurrence of antimicrobial resistant bacteria in healthy dogs and cats presented to private veterinary hospitals in southern Ontario: a preliminary study occurrence of antimicrobial resistant bacteria in healthy dogs a preliminary study," Canadian Veterinary Journal, vol. 50, no. 10, pp. 1047-1053, 2009.

[35] J. Ruiz, J. Gómez, M. M. Navia et al., "High prevalence of nalidixic acid resistant, ciprofloxacin susceptible phenotype among clinical isolates of Escherichia coli and other Enterobacteriaceae," Diagnostic Microbiology and Infectious Disease, vol. 42, no. 4, pp. 257-261, 2002. 